\title{
TETRALOGY OF FALLOT
}

\section{Tetralogy of Fallot with absent pulmonary valve syndrome: A 34-year African single centre experience}

Vijay Mammen, Paul Adams, Hopewell Ntsinjana and Antoinette Cilliers

Division of Paediatric Cardiology, Department of Paediatrics, Chris Hani Baragwanath Academic Hospital/University of the Witwatersrand, South Africa.

Address for correspondence:

Vijay Mammen

Chris Hani Baragwanath Academic Hospital

26 Chris Hani Road

Diepkloof

Johannesburg

1864

South Africa

\section{Email:}

vijay.mammen@wits.ac.za

\section{INTRODUCTION}

Absent pulmonary valve syndrome (APVS) is a rare congenital cardiac abnormality most commonly associated with Tetralogy of Fallot (TOF). It occurs in 3\% - 6\% of all infants and children presenting with TOF.(1.2) It was first described in 1864.(3) APVS with TOF is characterised by features of TOF with either rudimentary ridges or complete absence of the pulmonary valve tissue. This results in varying degrees of pulmonary stenosis and severe pulmonary regurgitation with massive dilatation of the proximal branch pulmonary arteries and compression of the tracheobronchial tree. Hence, respiratory symptoms are a common presenting feature in this condition. . $^{(4) 5)}$

In the current era, patients with this condition can be confidently diagnosed in utero with foetal echocardiography. ${ }^{(6)}$ However, foetal echocardiography is not readily available in public hospitals in resource constrained countries, making prenatal diagnosis uncommon. Approximately $40 \%$ - 50\% of these patients present as infants with respiratory symptoms ranging from stridor to severe respiratory compromise, requiring mechanical ventilation. ${ }^{(5,7)}$ Patients who present with respiratory symptoms early in life continue to pose a major clinical challenge associated with relatively high mortality rates, typically in the $20 \%$ - 30\% range. ${ }^{(5,7)}$ Preoperative ventilation predicts longer postoperative ventilation and increased mortality. ${ }^{(8)}$

\section{ABSTRACT}

Background: Absent pulmonary valve syndrome (APVS) is most commonly associated with Tetralogy of Fallot (TOF). TOF with APVS is characterised by features of TOF with either rudimentary ridges or complete absence of pulmonary valve tissue. This is often associated with varying degrees of pulmonary stenosis and severe pulmonary regurgitation with massive dilatation of the proximal branch pulmonary arteries, causing compression of the tracheobronchial tree. Hence, respiratory symptoms are a common presenting feature. Methods: Cases of TOF with APVS were extracted from the paediatric cardiology database at Chris Hani Baragwanath Academic Hospital (CHBAH) for January 198I - April 2016.

Results: A total of 15 patients with TOF and APVS were seen at CHBAH over the 34-year study period. TOF with APVS comprised $3 \%$ of all TOF patients. Ten (67\%) patients presented before I year of age. The majority of patients (67\%) had respiratory symptoms as their cause of presentation, of which 6 (40\%) were infants. Fourteen (93\%) patients were described to have the characteristic to-and-fro murmur at presentation. Five patients (33\%) were suspected of having 22qII.2 deletion syndrome, but only $\mathbf{4}$ were tested and $\mathbf{2}$ were found to be positive. A third of patients underwent surgical intervention and 4 of the 15 patients $(27 \%)$ were known to be alive at 10 years of age.

Conclusions: TOF with APVS compromised 3\% of all TOF patients, correlating with the literature. It is associated with the $22 \mathrm{qI} 1.2$ deletion syndrome and was suspected in $33 \%$ of patients. TOF with APVS should be strongly considered in a child less than I year presenting with respiratory symptoms and a characteristic to-andfro murmur. SAHeart 2018;15:128-132

A common finding in these patients is $22 \mathrm{q} 11.2$ deletion, with a frequency of approximately $44 \% .{ }^{(9)}$ The presence of the 22 l1.2 deletion is important to exclude because of the association with immunodeficiency, a worse prognosis and reduced survival. ${ }^{(10)}$

The survival rates after surgical intervention have improved over time. In a recent Australian study, the overall operative mortality was $13.5 \%$ over a 38 -year period. However, they showed no operative mortality in 15 consecutive patients 
since 2001. They attributed improved results over the last 12 years of the study to a combination of increased surgical experience, the application of extensive branch pulmonary artery reduction techniques and a trend towards increased utilisation of valved conduits. The overall survival in this study was $81.4 \% \pm 5.6 \%$ at 10 years. $^{(8)}$

There is currently no literature emanating from Africa that has been published on TOF with APVS. The aim of the study was to review the characteristics and outcomes of patients presenting with this condition at a tertiary African referral hospital.

\section{METHODS}

Data was sourced from the Chris Hani Baragwanath Academic Hospital (CHBAH), which is situated in the low-middle income South African township of Soweto, near Johannesburg. It serves a population of approximately 1.25 million people, including 128000 children under 5-years of age. ${ }^{(11,12)}$ Using a paediatric cardiology electronic database, cases of TOF and APVS were identified over a 34-year period from January 1981 - April 2016. Additional information, not obtainable from the database, was sought from patient files and extracted onto a standardised data collection form. Data collected included: age, gender, details of initial presentation, maternal history, anthropometry, clinical examination, results of genetic tests, chest $x$-ray reports, electrocardiography reports, echocardiography reports, angiography reports, surgical complications and outcomes which included morbidity and mortality.

Permission to undertake this research was obtained from the Human Research Ethics Committee (Medical) of the University of the Witwatersrand and the Medical Advisory Committee of $\mathrm{CHBAH}$.

\section{RESULTS}

A total of 15 patients with TOF and APVS were seen over the 34-year study period (Table I). APVS compromised 3\% ( $5 / 5$ |4) of all TOF patients.

Of the 15 patients, over two-thirds (67\%) were male. Ten (67\%) patients presented before I year of age. The majority of patients (67\%) had respiratory symptoms as their cause of presentation, of whom 6 (40\%) were infants.

Fourteen (93\%) patients were described to have the characteristic systolic and diastolic (to-and-fro) cardiac murmur on clinical examination at presentation.

Seven patients (47\%) were recorded to be dysmorphic. The FISH analysis for 22ql1.2 deletion was introduced at our institution in 1994, therefore documentation of testing was recorded from this period onwards. Five out of II (46\%) patients which presented after 1994 were suspected to have had $22 \mathrm{q} 1 \mathrm{l}$. I deletion. Of these 5 patients, 2 patients were positive for $22 \mathrm{q} \mid \mathrm{l} .2$ deletion, I patient was negative for 22 l1.2 deletion, I patient's blood was rejected by the laboratory and I patient was not tested. An additional patient showed phenotypical features of Noonan's syndrome for which there is presently no genetic test available in South Africa (Table I).

A number of patients with TOF and APVS had other associated cardiac features. Six patients (40\%) were documented to have a right aortic arch. Both patients that were positive for $22 q 11.2$ deletion had a left aortic arch. Of the other 3 patients that were suspected to have $22 \mathrm{q} / 1.2$ deletion, only 2 patients had a right aortic arch. Patient 6 (Table I) had a small secundum atrial septal defect (ASD) and a left superior vena cava (SVC) diagnosed on echocardiography. Patient 12 had a single right coronary artery and a left SVC draining into the coronary sinus. Patient 13 was documented to have a $4 \mathrm{~mm}$ secundum ASD. Patient 14 had a quadricuspid aortic valve, but no aortic stenosis or regurgitation was noted.

Only 5 (33\%) patients underwent surgical intervention (Table I). The majority were done between 1981 and 1998, and in children older than a year of age.

Patient I had a transannular patch and ventricular septal defect (VSD) closure at 9 years of age, followed by placement of a pulmonary homograft and closure of a small residual VSD 2 years later. Patient 3 had a VSD closure at II years of age. According to the surgical notes reconstruction of the pulmonary outflow tract was not done because the pulmonary valve dysfunction was deemed to be mild at the time. Patient 8 had a pulmonary homograft and VSD closure at 8 years of age. Patient 12 had reconstruction of the main pulmonary artery and VSD closure at 2 years of age. Patient 14 had a pulmonary homograft and VSD closure at 6 months of age at a private hospital. Patient 9 planned to have surgery abroad and was lost to follow up. There were no records of surgical intervention in the other patients.

Recently a patient with TOF and APVS, who presented at 26 months of age with an incidental murmur, underwent bronchoscopy to assess the severity of bronchial compression pre-operatively. The bronchoscopy showed 90\% compression of the right main bronchus and 30\% of the left main bronchus. The patient has been lost to follow up without surgery being done. 
TABLE I: Characteristics of patients with TOF and APVS.

\begin{tabular}{|c|c|c|c|c|c|c|c|c|}
\hline No. & $\begin{array}{l}\text { Year of } \\
\text { presenta- } \\
\text { tion }\end{array}$ & Sex & $\begin{array}{l}\text { Age of } \\
\text { presentation }\end{array}$ & $\begin{array}{l}\text { Symptoms on } \\
\text { presentation }\end{array}$ & Syndromes & Surgical intervention & Alive & Notes \\
\hline I & 1981 & Male & 2 months & Shortness of breath & Not dysmorphic & $\begin{array}{l}\text { Transannular patch andVSD } \\
\text { closure in 1990. Pulmonary } \\
\text { homograft and closure of } \\
\text { small residual VSD in } 1992\end{array}$ & Unsure & Last seen 2012 \\
\hline 2 & 1982 & Male & 5 weeks & Incidental murmur & $\begin{array}{l}\text { Phenotypical } \\
\text { features of } \\
\text { Noonan's } \\
\text { syndrome }\end{array}$ & Nil & Unsure & Last seen 1997 \\
\hline 3 & 1983 & Female & 14 months & Respiratory distress & Not dysmorphic & $\begin{array}{l}\text { VSD closure only in } 1993 . \\
\text { Pulmonary homograft } \\
\text { not done }\end{array}$ & Unsure & $\begin{array}{l}\text { Last seen } 1997 . \\
\text { Was awaiting } \\
\text { pulmonary } \\
\text { homograft }\end{array}$ \\
\hline 4 & 1994 & Male & 12 days & Respiratory distress & Not dysmorphic & Not done & Unsure & Last seen 1995 \\
\hline 5 & 1994 & Female & I month & Incidental murmur & $\begin{array}{l}\text { Clinically } 22 \text { q I I.2 } \\
\text { deletion syndrome. } \\
\text { Blood specimen } \\
\text { rejected }\end{array}$ & Not done & Unsure & $\begin{array}{l}\text { Last seen } 1994 . \\
\text { Plan was for cardiac } \\
\text { catheterisation }\end{array}$ \\
\hline 6 & 1995 & Male & Day I of life & $\begin{array}{l}\text { Respiratory distress, } \\
\text { distended abdomen }\end{array}$ & $\begin{array}{l}\text { Suspected } 22 \mathrm{q} \mid \mathrm{I} .2 \\
\text { deletion syndrome. } \\
\text { Not tested }\end{array}$ & Nil & No & $\begin{array}{l}\text { Died in ICU at } \\
\text { I month of age, } \\
\text { ventilated since } \\
\text { birth }\end{array}$ \\
\hline 7 & 1997 & Male & 4 months & $\begin{array}{l}\text { Cough and } \\
\text { shortness of breath }\end{array}$ & Not dysmorphic & Not done & Unsure & $\begin{array}{l}\text { Last seen } \\
\text { cardiac clinic }\end{array}$ \\
\hline 8 & 1998 & Female & 7 years & $\begin{array}{c}\text { Cough and } \\
\text { incidental cardiac } \\
\text { murmur }\end{array}$ & Not dysmorphic & $\begin{array}{l}\text { Pulmonary homograft and } \\
\text { VSD closure in } 1998\end{array}$ & Unsure & Last seen 1999 \\
\hline 9 & 1998 & Male & 10 years & $\begin{array}{l}\text { Incidental cardiac } \\
\text { murmur }\end{array}$ & Not dysmorphic & $\begin{array}{l}\text { Not done. For surgical } \\
\text { intervention abroad as } \\
\text { requested by family }\end{array}$ & Unsure & Last seen 1998 \\
\hline 10 & 2005 & Male & Day I of life & $\begin{array}{l}\text { Mild respiratory } \\
\text { distress with cardiac } \\
\text { murmur }\end{array}$ & Not dysmorphic & Not done & Unsure & $\begin{array}{l}\text { Last seen } 2005 . \\
\text { Was for cardiac } \\
\text { catheterisation in } \\
6 \text { months' time }\end{array}$ \\
\hline 11 & 2008 & Female & 2 months & $\begin{array}{l}\text { Gastroenteritis. } \\
\text { Incidental cardiac } \\
\text { murmur }\end{array}$ & $\begin{array}{l}\text { Positive for } 22 q \mid 1.2 \\
\text { deletion syndrome }\end{array}$ & Not done & Unsure & Last seen 2008 \\
\hline 12 & 2014 & Male & I year I month & Respiratory distress & $\begin{array}{l}\text { Positive for } 22 q \mid 1.2 \\
\text { deletion syndrome }\end{array}$ & $\begin{array}{l}\text { Reconstruction of pulmonary } \\
\text { artery and VSD closure in } \\
\text { 2015. Transannular patch } \\
\text { or pulmonary homograft } \\
\text { not done }\end{array}$ & Yes & Last seen 2016 \\
\hline 13 & 2015 & Female & 2 year 2 months & Cardiac murmur & $\begin{array}{l}\text { Negative for } \\
22 \text { I l } 1.2 \text { deletion } \\
\text { syndrome }\end{array}$ & Awaiting surgery & Yes & $\begin{array}{l}\text { Last seen } 2016 \text { - } \\
\text { awaiting surgery }\end{array}$ \\
\hline 14 & 2015 & Male & 6 months & $\begin{array}{l}\text { Respiratory distress } \\
\text { with incidental } \\
\text { cardiac murmur }\end{array}$ & Not dysmorphic & $\begin{array}{l}\text { Pulmonary homograft and } \\
\text { VSD closure in } 2016\end{array}$ & Unsure & $\begin{array}{l}\text { Patient transferred } \\
\text { to private hospital }\end{array}$ \\
\hline 15 & 2016 & Male & 8 months & $\begin{array}{l}\text { Shortness of breath } \\
\text { with incidental } \\
\text { cardiac murmur }\end{array}$ & Dysmorphic & Not done yet & Yes & Last seen 2016 \\
\hline
\end{tabular}

Review of follow-up data showed that 7 (47\%) patients were known to be alive at I year of age while 4 (27\%) were known to be alive at 10 years of age. One patient died during the neonatal period. The follow up of patients improved over the last 3 years of the study period. Three out of the 4 patients that have presented since 2014 , continue to be followed up at the cardiac clinic.

Figures I - 4 show 2 echocardiographic and 2 angiographic images for Patient 13 which demonstrate typical features of TOF with APVS. 


\section{DISCUSSION}

To our knowledge, this is the first African study on TOF with APVS. No literature pertaining to TOF and APVS in Africa could be found using an online literature search. Our data is in agreement with the published literature which shows that APVS is a rare congenital cardiac lesion, compromising 3\% of all TOF patients. ${ }^{(1,2)}$ Ten (67\%) patients presented before I year of age in our study. Typically, patients with TOF and APVS are divided into 2 categories: those who present early with respiratory symptoms (infant-type APVS) and those who present later (childhood-type). ${ }^{(5,13)}$ The majority of the study patients (67\%) had respiratory symptoms as their cause of

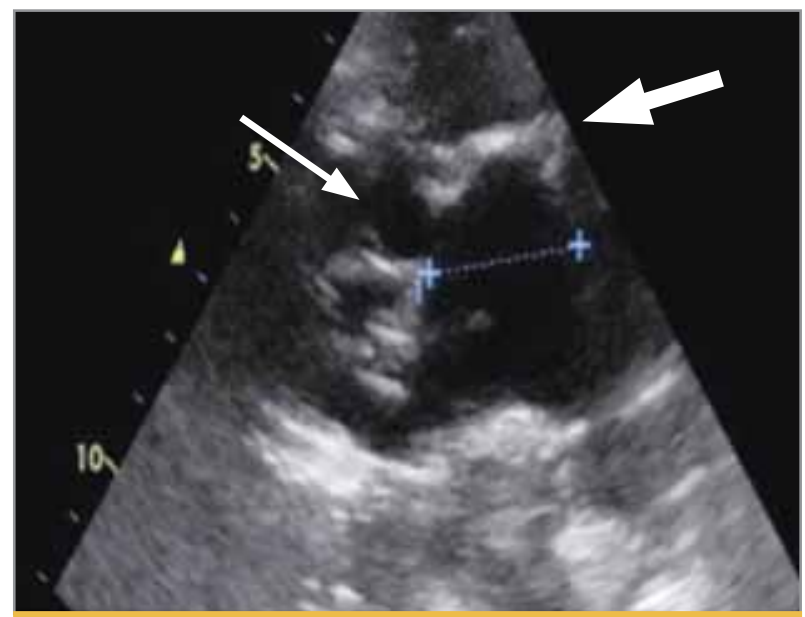

FIGURE I: (Patient I3) Echocardiographic image in the parasternal short axis view: The pulmonary valve (thick arrow) appears thickened. The main pulmonary artery is massive compared to the ascending aorta (thin arrow).

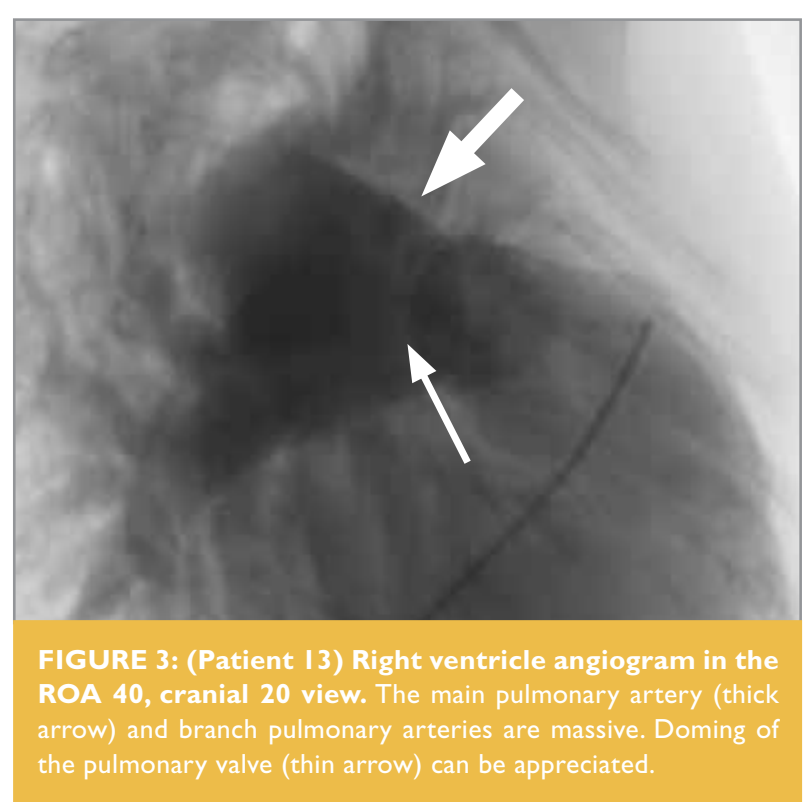

presentation, of which 6 (40\%) were infants. A to-and-fro murmur (ejection systolic and early diastolic murmur) at the left sternal border is a characteristic clinical sign in TOF and APVS. ${ }^{(7,13)}$ The majority of our patients (93\%) had a to-andfro murmur on clinical examination which was diagnostic at presentation. Given the limited availability of prenatal ultrasound in a resource poor setting like ours, TOF and APVS should be suspected in a child less than I year presenting with respiratory symptoms and a characteristic to-and-fro murmur.

As 22q 11.2 deletion is a common finding in patients with TOF and APVS, routine screening for this deletion should be

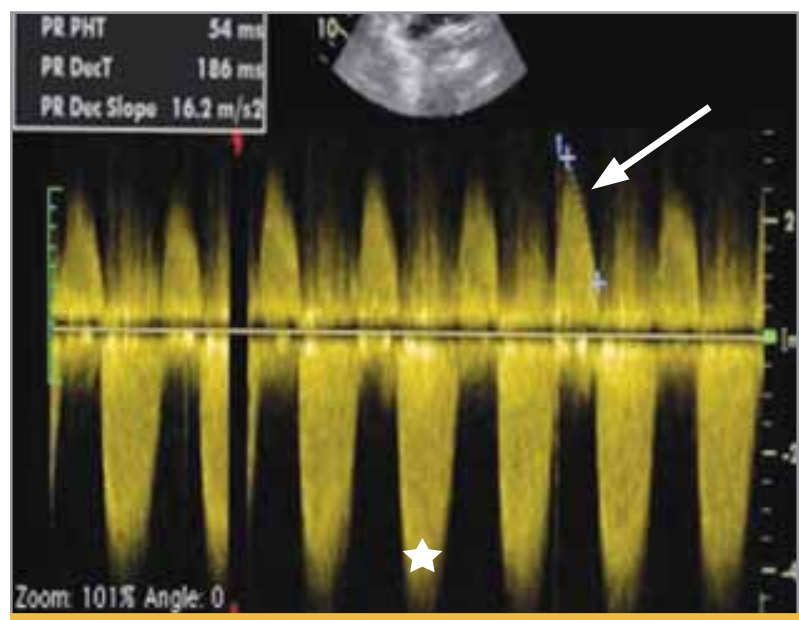

FIGURE 2: (Patient | 3) Echocardiographic image showing severe pulmonary stenosis (velocity $>4 \mathrm{~cm} / \mathrm{s}$, star) and pulmonary regurgitation (PHT $54 \mathrm{~ms}$, arrow) using continuous wave Doppler across the pulmonary valve.

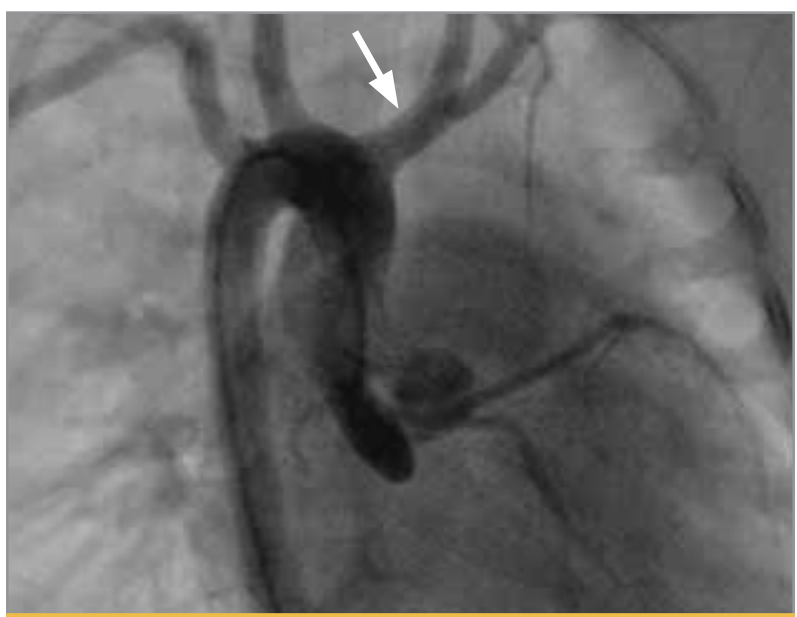

FIGURE 4: (Patient I3) Ascending aorta angiogram in the AP view showing a right aortic arch with a mirror image branching pattern. The first branch arising from the ascending aorta (arrow) is the innominate artery. 
encouraged. The 22ql1.2 deletion syndrome was suspected in 5 out of II of patients (46\%). According to the literature, the frequency of this deletion in TOF with APVS is approximately $44 \%{ }^{(9)}$ The laboratory test for 22 q 1 . 2 deletion was introduced in 1994, therefore the patients presenting before this testing era were not tested. Routine screening for confirmation of 22q 1 I.2 deletion in patients with TOF and APVS should be routine particularly because of its association with other complications such as immunodeficiency and mental retardation which has an impact on management and outcome. . $^{(9,10)}$

TOF with APVS may occasionally be associated with defects such as atrial septal defects and absent left pulmonary artery. ${ }^{(13)}$ Two patients had an ASD secundum and 2 patients had a left SVC. A right aortic arch has been previously documented in approximately $70 \%$ of patients who are positive for $22 \mathrm{q} 11.2$ deletion. ${ }^{(8)}$ In our study, $40 \%$ of patients were found to have a right aortic arch, however, both patients that were confirmed positive for $22 \mathrm{q} \mid \mathrm{I} .2$ deletion had a left aortic arch. Of the other 3 patients that were suspected to have 22 q 1 .2 deletion, 2 had a right aortic arch.

Only I of our patients underwent bronchoscopy as part of a pre-operative assessment of the airways. Bronchoscopy has been shown to be a beneficial pre-operative investigation to assess the degree of airway compression and to guide surgical management. A recent study on airway compression management in late-presenting APVS showed 7 out of 19 (37\%) patients had pre-operative evidence on bronchoscopy of airway compression that needed surgical intervention. Four patients underwent a pulmonary artery reduction plasty and 3 patients underwent the Lecompte manoeuvre. ${ }^{(14)}$

Adequate surgical data was available in only 5 patients. Of the 10 remaining un-operated patients, only I was confirmed to have died before 5 weeks of age. The other 9 patients were lost to follow up and may have died, or have had surgery at another institution. One patient was documented to have travelled abroad for surgery. Patients referred to our institution include patients from neighbouring provinces and countries who are difficult to trace.

Follow-up data of the study patients is poor, with only 4 (27\%) of the 15 patients known to be alive at 10 years of age. One patient died in the neonatal period. Seven (47\%) patients were alive at I year of age. The potential for good outcomes was documented in a study by Yong et al. in Australia over a 38-year period, which showed that the overall survival at 10 years was $81.4 \% \pm 5.6 \%{ }^{(8)}$
In conclusion, TOF with APVS is a rare condition compromising $3 \%$ of all TOF patients presenting to an African tertiary care centre, which correlates with the mainstream literature. The $22 \mathrm{q} 11.2$ deletion syndrome was suspected in $33 \%$ of patients but confirmed in a small number (13\%), largely due to several of our patients presenting prior to the availability of routine testing. APVS should be suspected in a child less than I year presenting with respiratory symptoms and a characteristic toand-fro murmur. A good outcome can be expected if diagnosed early and the appropriate surgical management provided.

The limitations of the study were that the data was analysed retrospectively at a single institution which has historically experienced numerous resource constraints, and where follow up of patients has been poor. As such, any inferences drawn from these data were limited.

\section{Conflict of interest: none declared.}

\section{REFERENCES}

I. Lev M, Eckner FA. The pathologic anatomy of tetralogy of Fallot and its variations. Dis Chest. 1964;45:251-61.

2. Rao BN, Anderson RC, Edwards JE. Anatomic variations in the tetralogy of Fallot. Am Heart J. 1971;8I (3):36I-7I.

3. Chevers $N$. Recherches sur les maladies de l'artère pulmonaire. Arch Gen Med 1847; 15:488-508

4. Macartney FJ, Miller GA. Congenital absence of the pulmonary valve. $\mathrm{Br}$ Heart J. 1970;32(4):483-90

5. Kirshbom PM, Kogon BE. Tetralogy of Fallot with absent pulmonary valve syndrome. Semin Thorac Cardiovasc Surg Pediatr Card Surg Annu. 2004; 7:65-71.

6. Volpe P, Paladini D, Marasini M. Characteristics, associations and outcome of absent pulmonary valve syndrome in the fetus. Ultrasound Obstet Gynecol. 2004;24(6):623-8.

7. Brown JW, Ruzmetov M, Vijay $P$, et al. Surgical treatment of absent pulmonary valve syndrome associated with bronchial obstruction. Ann Thorac Surg. 2006;82:2221-6.

8. Yong MS, Yim D, Brizard CP, et al. Long-term outcomes of patients with absent pulmonary valve syndrome: 38 years of experience. Ann Thorac Surg. 2014;97(5):167|-7.

9. Momma K. Cardiovascular anomalies associated with chromosome 22q | 1.2 deletion syndrome. Am J Cardiol. 2010;105(1 I):1617-24.

10. Kobayashi DI, Sallaam S, Humes RA. Tetralogy of Fallot with complete DiGeorge syndrome: Report of a case and a review of the literature. Congenit Heart Dis. 2013;8(4):El 19-26.

11. Actuarial society of South Africa (ASSA). Full and provincial AIDS and Demographic models. Available at http://aids.actuarialsociety.org.za/default. asp? pageid=3282. (Date accessed: 10 December 20 | 6.)

12. Chris Hani Baragwanath Hospital website. General information. Available at: http://www.chrishanibaragwanathhospital.co.za.

(Date accessed: 10 December 2016.)

13. Wu W, Pang K, Zhang A, et al. Echocardiography in the diagnosis of patients with absent pulmonary valve syndrome: A review study of 12 years. Int J Cardiovasc Imaging. 2015;3 I (7): 1353-9.

14. Martinez-Esteve Melnikova A, Sologashvili T, Beghetti M, et al. Airway compression management in late-presenting absent pulmonary valve syndrome. Cardiol Young. 2015;25(2):295-30. 